\title{
Head Nurses' Perception of Educational Needs for Acquiring Managerial Competence at Intensive Care Units: A Qualitative Study
}

\author{
Roghieh Nazari, ${ }^{1}$ Zohre Vanaki, ${ }^{1, *}$ Sima Mohammad Khan Kermanshahi, ${ }^{1}$ and Ebrahim \\ Hajizadeh $^{2}$ \\ ${ }^{1}$ Department of Nursing, Faculty of Medical Sciences, Tarbiat Modares University, Tehran, IR Iran \\ ${ }^{2}$ Department of Biostatistics, Faculty of Medical Sciences, Tarbiat Modares University, Tehran, IR Iran \\ ${ }^{*}$ Corresponding author: Zohreh Vanaki, Department of Nursing, Faculty of Medical Sciences, Tarbiat Modares University, Tehran, IR Iran. Tel: +98-9123840601, Fax: +98-2182883856, \\ E-mail:vanaki_z@modares.ac.ir
}

Received 2015 December 21; Accepted 2015 December 23.

\begin{abstract}
Background:In dealing with the new challenges of the health system, the head nurses of intensive care units need continuing educational programs, and investigating the learning requirements is the infrastructure of developing human resources.

Objectives: This study aimed to assess the educational needs of the head nurses of intensive care units.

Materials and Methods: This qualitative study was conducted during year 2014. Data collection was done through semi-structured and in-depth face-to-face interviews with ten head nurses of the intensive care units of hospitals located in Mazandaran province. Data analysis was carried out with the conventional method of qualitative content analysis.

Results: After data analysis and extraction of 300 primary codes, 21 categories and four main themes were identified. The themes included "scientific needs", “artistic needs", “technical needs” and “organizational needs”, which partially overlapped.

Conclusions: The data of this study showed that for obtaining managerial competence in these units, the head nurses of intensive care units need some instructions to satisfy their scientific, artistic, technical and organizational needs. Proper planning and implementation of continuous in-service education based on these training requirements paves the way for providing hospitals with nurses competent for managing the intensive care units.
\end{abstract}

Keywords: Educational Needs, Head Nurse, Intensive Care Unit, Managerial Competency, Continuing Education

\section{Background}

Continuous education results in improvement in the level of nursing personnel's knowledge, awareness and performance, however such in-service education has high costs for the hospitals (1).

Most hospitals have recognized the head nurses' need for continuing educational programs to help them improve their knowledge and skills (2). Various studies have confirmed the need for continuous courses on management training for head nurses to deal with the new challenges of the health system (3), and they have emphasized on training head nurses as leaders as part of in-service education (4).

Nevertheless, providing education without examining educational requirements is unlikely to be efficient as educational needs are actually the gap between what we know and what we must know $(5,6)$. Educational needs assessment is the best way for understanding the challenges faced by health service providers so that the most relevant instructions could be organized into their educational programs (7). This necessity is felt for the head nurses of the intensive care units (ICU) since these units are one of the major parts of the health care system (8) and according to the changes in the health system and in technology and equipment, and also regarding the evolution of care, the role of their head nurses has become increasingly complicated (9).

There are different ways for studying educational needs, including questionnaires, interviews, focus groups, audit charts, and standard patient and workplace overviews (10). The aforementioned qualitative methods need valid predefined tools and they may not be able to present problems and their potential solutions; however, a qualitative interview with experienced people can represent the depth of their insight and their views, and their knowledge, attitude and skills needed for this profession. Hence, researchers believe that qualitative methods are more appropriate for examining the educational needs of sophisticated subjects. Since no study has been performed in Iran regarding the special educational needs of the head nurses of intensive care units, this study was conducted due to the significant role of this group in providing care for critically ill patients on the one hand, and

Copyright ( 2016, Baqiyatallah University of Medical Sciences. This is an open-access article distributed under the terms of the Creative Commons Attribution-NonCommercial 4.0 International License (http://creativecommons.org/licenses/by-nc/4.0/) which permits copy and redistribute the material just in noncommercial usages, provided the original work is properly cited. 
Nazari Retal.

nurses' urge for offering a scientific and safe care on the other hand.

\section{Objectives}

This study aimed to assess the educational needs of the head nurses of intensive care units.

\section{Materials and Methods}

In this research the qualitative research method with a content analysis approach was used to obtain the head nurses' educational needs through recognizing the required kinds of competence for achieving field-based managerial competence. The participants were ten head nurses of intensive care units of hospitals located in Mazandaran province. The participants had at least two years of experience as a head nurse at this unit and they purposefully participated in this study. Since qualitative data identify a wider range of learning needs and opportunities for developing educational programs compared to quantitative methods (11), and as they are known as a useful method for investigating the educational needs of the learners (10), semi-structured and in-depth faceto-face interviews were used. The interviews began with questions such as: "tell us about what you do daily", "have you ever needed any special skill or knowledge for performing these functions?", "say some concrete instances of this sort". During the interview exploratory questions were used, such as "explain more about this or give an example". These questions were asked to obtain rich and deeper data and obtain insight on hidden data.

The content of the face to face interviews was recorded using a tape recorder and transcribed on paper by the researcher. Data collection continued until data saturation and to a point that no new description was obtained.

Since the content analysis approach is a subjective interpretation of the content of a large amount of data through the process of coding, systematic classification and identification of substances or patterns (12), in this study, conventional three-phase content analysis (Elo, Kyngas 2008) (13) was used for data analysis. The first phase is prepared through immersion of data and obtaining a general sense of the findings, choosing the analysis unit, and making a decision about the obvious or the hidden content. Then, the second phase is an organization step, during which the coding system is developed and the groups appear, this is done by classifying the codes, categories and the related branches; a general description of the subject is formulated. The third phase is the reporting step, including the analysis procedure, after which the results are reported (13). Box 1 illustrates the way a sample of categories is formed and Box 2 displays the way one of the main themes is made.

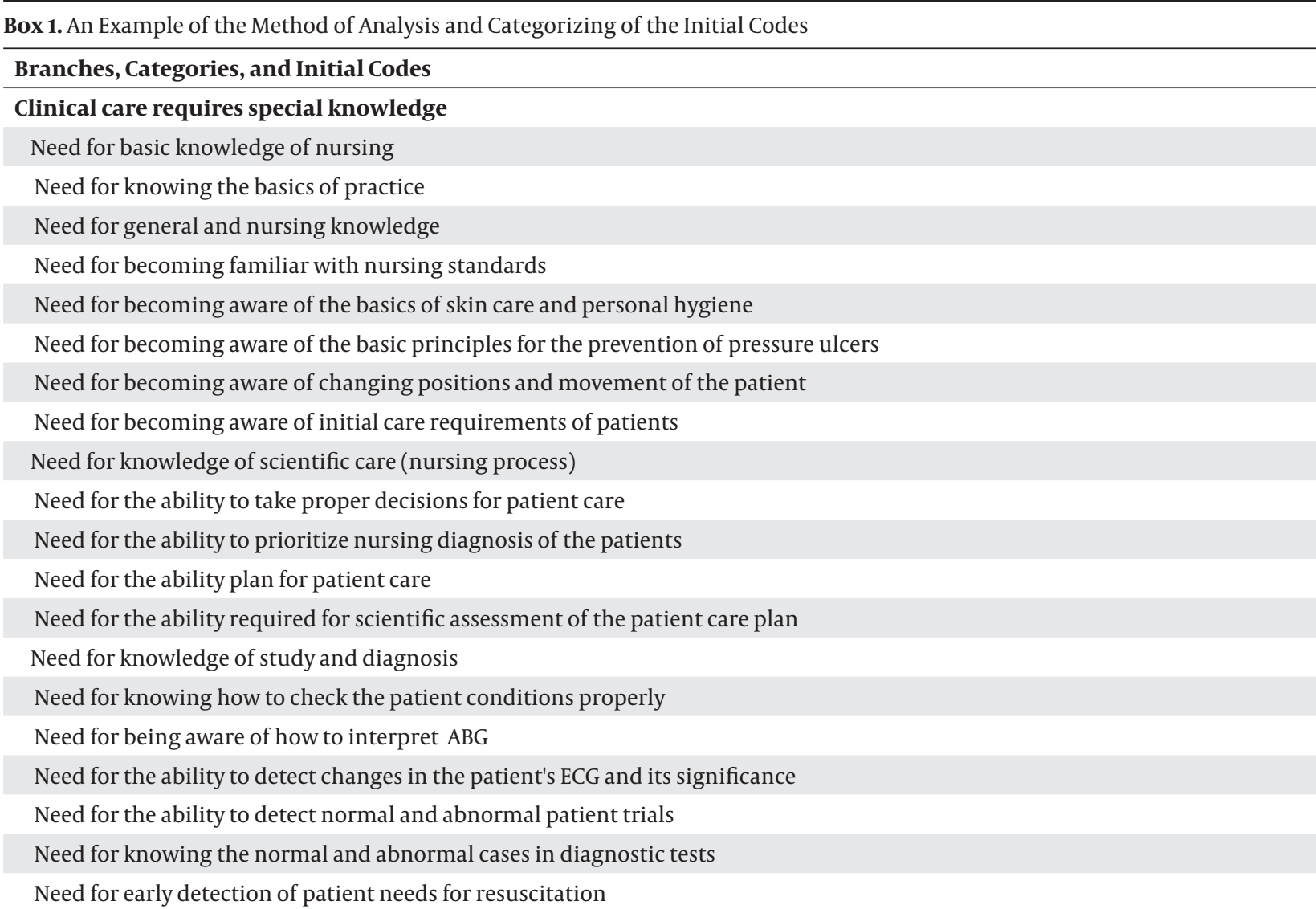


Nazari Retal.

Need for the ability to recognize the patient needs for intubation

The need for knowledge of treatment

Needs for scientific capability in the field of treatment of diseases

Need for understanding the side effects of medications

Need for detecting the protocols of blood transfusion

Need for the ability to apply regenerative medicine

Need for the ability to coordinate cardiopulmonary resuscitation

Need for special nursing knowledge

Need for knowledge on the care of critically ill patients

Need for reviewing the specialized knowledge about intensive care units

Need for being aware of patient care under a ventilator

Need for being aware of the risk factors causing complications for ICU patients

Box 2. The Main Themes and Their Branches and Categories

The Main Themes, Branch, Category

Academic needs

Need for management knowledge

Strategic management

Managing the process of change

Participatory decision-making

Team management

Organizing the unit

Strict monitoring

Planning

Knowledge management

Crisis management

Need for the knowledge and skills of scientific research

How to find resources

Research methodology

The need for obtaining knowledge about intensive clinical care

Basic knowledge of nursing

Knowledge of scientific care (nursing process)

Knowledge of study and diagnosis

Knowledge of treatment

Knowledge of intensive nursing

Need for acquiring knowledge on teaching and learning principles

Mentoring

Patient education

Training needs assessment

Staff training

Need for acquiring knowledge and skills of the Modern care

Spiritual care

Evidence-based care 
To increase the reliability of the data, the participants and a number of professors reviewed the study protocol and findings. The researchers tried to ensure the data stability by taking measures such as giving feedback to the participants and the research team. To create verifiability, the researchers tried to fully describe all the research phases, including data collection, analysis and forming the themes. Also, to achieve better transmission capabilities, targeted sampling was used and it was found that the participants had great variety in terms of work experience and place of work.

This study was approved by the ethics committee of Tarbiat Modares University. For conducting the interview, a written consent was obtained from the participants. To enter the research environment and for conducting the study, the consent of the hospital authorities was obtained. All the names were coded as the tapes were being transcribed, and throughout the analysis and reporting of the results, references were made to these codes. The participants were assured that the obtained data would remain confidential and the results would be published without citing their names.

\section{Results}

Data analysis led to the extraction of over one hundred initial codes. After merging the codes, omitting the overlapped ones and categorizing them, 21 categories and four main themes were obtained. Data analysis showed that the head nurses of the intensive care unit had four kinds of educational needs for acquiring managerial competence, which were the same themes as that proposed by the researchers. All of the themes overlapped with each other to some extent. As illustrated by Figure 1, these needs included, "scientific needs", "artistic needs", technical needs", and "organizational needs".

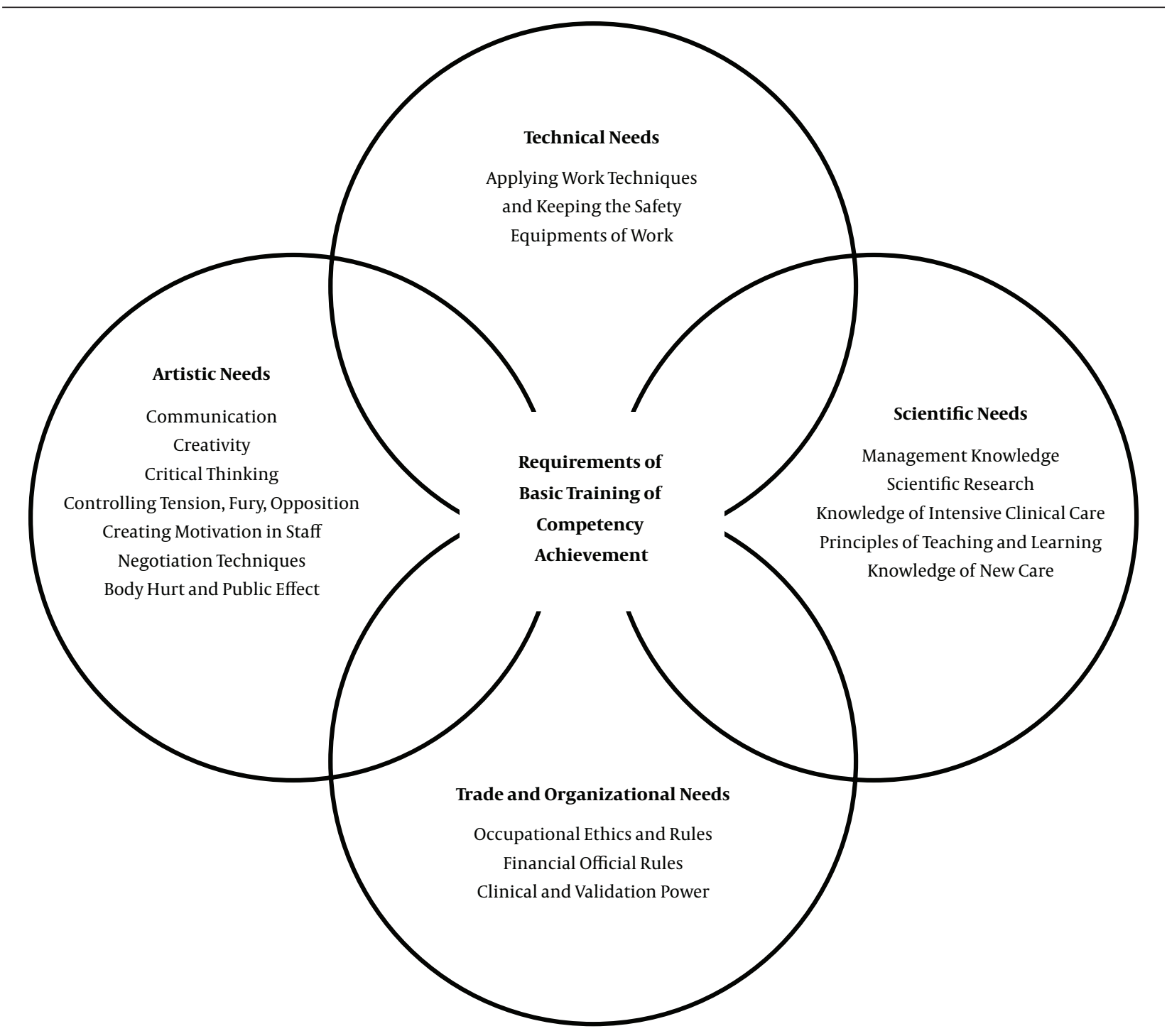

Figure 1. The Main Themes of Educational Needs of Head Nurses at Intensive Care Units 
Nazari Ret al.

\subsection{Academic Needs}

The categories, which resulted in the formation of this theme, were actually related to scientific concepts required by the head nurses of intensive care units. These categories included the need for managing knowledge, the need for knowledge and skills in scientific research, the need for acquiring knowledge about intensive clinical care, the need for acquiring the knowledge on teaching and learning principles, and the need for acquiring knowledge and skills for new methods of care.

The participants stated that one of their educational needs for gaining managerial competence was acquiring management knowledge in the fields of strategic management, process and change management, participatory decision making, team management, unit organizing, strict monitoring, planning, and managing knowledge and crisis. For instance the participants expressed their experience in this way:

"When I was a head nurse, I did not take these courses (management courses) at all. Like other people or like most of them, I used to think that management is something inborn. But, now that I have participated in some of classes, I have realized that if I had this knowledge (management knowledge), I would have performed better" P1.

Participant number 10 talked about an experience that was representative of the head nurses' need for awareness of management knowledge. "Ms. A was an auxiliary nurse who had retired, based on her experience; during her role as a head nurse she would give soft food rather than liquids to the patients for whom the endotracheal tube was removed and they started to eat food and it was interesting that the patients would tolerate it. Recently, one of the trainers said that she/he has read this matter in an article. Such experiences were lost when Ms. A retired" P10.

Regarding the planning and organizing forces, a great deal of experience was retrieved including the following:

"Today in bed number 1, there was a pre-eclampsia patient and in bed number 3 there was a patient with diabetic ketoacidosis (DKA), so, I assigned them to a more potent nurse, while in bed number 11, there was an intubated patient, so I assigned him to a less potent nurse. Thus, the functions are shared among the personnel according to their capability and also the patients' needs" P5.

One of the other educational needs on which the participants emphasized was the need for knowledge and skills for scientific research and valid recourses. For example, a participant stated, "we have graduated long ago. Now, thanks to the resources on the internet our gap in knowledge could be over come yet we must be able to have access to such resources, for example, about the difference in opinion about wound care; to cover it or to uncover it?" P8.

Also, they expressed their need to become familiar with research methodology; for instance, one of the participants said "what a large number of patients and works at the unit that can be studied. But when I wanted to start I found that I could not. I neither had the time nor the ability." P3.

The participants believed that a competent head nurse must be firstly a good nurse at the intensive care unit. Therefore, she/he must have sufficient knowledge about the clinical care conducted at the intensive care unit. They thought of basic nursing knowledge, scientific care based on the nursing process, knowledge for study and recognition, knowledge for treating diseases and knowledge for intensive nursing, as necessities for a head nurse. Some of the retrieved quotations were as follows:

“When you don't know what an under-ventilator patient needs, when you don't know the device and its application, how can you control if this personnel is functioning properly or not?" P3.

These participants believed that a head nurse must have capabilities in training the staff, patients and students, and achieving this capability necessitates training, educational principles of mentoring, educational needs assessment. The following quotations are in this regard:

"When there is a new staff, I should start to teach all the required information to him/her. When I am less busy, I control all the staff in terms of their knowledge and performance. I provide them with educational programs and discussions" P1.

The participants stated that a head nurse must be able to understand and create an appropriate educational situation. "In the early morning at the time of shift changes there is a patient who has a fever. This is the best occasion to teach the personnel on how to deal with a patient with fever" P3.

In regards to the need for assessment of education, one of the participants stated, "at the audit time of the unit, the head nurse tells the nurse assistants what the problem of that unit is, for example the way of report writing, the way of wound dressing, etc. Then the head nurse holds or suggests a training program for the personnel" P9.

In addition, the participants mentioned some new requirements in the field of spiritual care and evidencebased care, which are new topics in patient care. "A head nurse can make the students get closer to the spirit of God with his/her doings like praying even when they are by the patients" $\mathrm{P} 5$.

There were also quotations, which implied the importance of evidence-based care like "there are new methods of care and treatments like monitoring the cuff pressure or closed suction. I am a senior expert and because of that I study articles and I have become familiar with these. But others cannot make use of research evidence" P9.

\subsection{Artistic Needs}

The head nurses' experiences showed that to get managerial competence, they need some artistic competencies which include communication, creativity, critical thinking, controlling tension, fury and opposition, creating 
motivation in the staff, negotiation techniques and eventually body language and public effect.

In relation to communication, participant number 3 stated, "the ICU is a stressful unit. But if the head nurse can behave properly, she/he can prevent at least 70 percent of the tensions" P3.

The participants stated that there are many occasions in the unit, which is unique and needs creative decisionmaking. "I have placed all the basic required devices by each patient so that the nurses hardly leave the patients alone to get these devices" P1.

The participants stated that they should not obey the orders blindly. "There are some things that we remind the doctors of and we find faults with them. We should not blindly accept whatever they say" P10.

"For the patient who had a good blood pressure at the beginning and now suffers from hypotension, our duty is not just checking the blood pressure, but we must have a diagnosis and detect its probable cause" P9.

The above quotations express some of the aspects of the skills for critical thinking. All participants thought of the intensive care unit as a unit with potential for much tension. Therefore, they believed that they must be able to overcome the tensions and oppositions while controlling their anger.

"At this moment, I might treat them harshly, but the next day I behave in a way as if nothing has happened, i.e. I try to forget yesterday and not continue my yesterday's behavior" P7.

"Once there was a fight between Ms A and Dr. C. I talked to Dr. C and asked him/her to revise his/her behavior. Of course, I talked to the doctor in a way that she/he does not get upset and she/he only finds out her/his mistake." P3.

All participants emphasized on the significance and necessity of motivation for work at the intensive care unit. In this regard, participant number 1 cited the role of the head nurse in increasing the motivation of the staff at the intensive care unit; "the staff at the ICU must have motivation. If I assist them to the most possible extent or provide some facilities for them, they will certainly work better" P1.

The participants stated that for satisfying the unit requirements and managing the staff, they should negotiate with the authorities and sometimes even implore them. "I present evidence and convince the authorities that this workforce is not qualified for this unit". They believed that the head nurse of ICU must have the the ability to impact upon others. "The authorities do not listen to my words ... Dr. A (the head) applies most of my suggestions and words" P5.

\subsection{Technical Requirements}

The technical needs actually include those with the most psychomotor dimension. This theme consists of classes of technology application, working and keeping equipments, the skill of intensive clinical care, control- ling infection, and work safety. The participants thought of the need for being trained to work with computers as one of their major technical requirements. They believed that they must be able to work with computers, whether for recording and following the works or for internet communication, and also for satisfying the need for scientific resources.

"Now that all the nursing works and services must be recorded on the system, certainly we cannot work without familiarity and skills for computers" P3.

The participants counted the presence of many devices and equipments as one of the features of special units. For example, one of them stated, "now we have about 60 - 70 devices in the ICU; we must be assured that the personnel can work with them and also can keep them, and I should also be sure about its proper use" P2.

The participants stated that attention to and awareness of what improves the staff's work safety and what results in safety in patient care has great importance in the special unit. "Safe and helpful care, for both the patient and the nurse, brings about less hurt to the patient" P4.

\subsection{Organizational Needs}

The four categories, which created the theme of organizational need, were the requirements created as a result of attendance in the nursing class or the changes and priorities of the organization. These categories include ethics, professional rules, financial-official rules, clinical authority and validation.

All the participants accepted their knowledge shortage in ethics and professional rules and they stated that they had not received any training in this relation during their higher education and if they had had any, it had been too poor.

"I used to associate ethics to mood and these sorts of things until last week when I took the occupational ethics class. Thereafter, I found that I had mistaken. That is because we have not read anything in this relation before" P9.

The subjects of this study knew the need for awareness of financial and official issues was important because of three aspects; firstly for following their own rational and logical requests, secondly to defend their subordinate staff, and thirdly for significant and efficient presence in the meetings.

"When you take part in a meeting or when you have an official or financial request, they will easily get rid of you if you do not know their rules. Or optimistically speaking, when you know the financial-official rules you can have both rational requests and make use of the opportunities for improve things" P1.

The participants thought of the role of head nurses in the intensive care unit to be important in the implementation and monitoring, validation process and clinical authority; hence they believed in the necessity of awareness about its implementation process. For example, one 
Nazari Ret al.

participant stated, "we are very involved in validation. Some things in this relation like logging, controlling infection and audit, are very good and they contribute to improving things. I should know them" P2.

\section{Discussion}

The results of this study showed that the head nurses at the intensive care unit must take formulized training in different domains. Other studies too, have confirmed the hospital nursing managers' need for educational courses in dealing with new challenges in the health system (3). Nowadays, the head nurses must be skillful in management so that they are able to respond to the needs of patients, unit staff, and their work organization (2). Therefore, in developed countries, most hospitals have recognized the need for continuing educational programs for the head nurses (14). However, the question is, what educations do the head nurses need for achieving managerial competence at the intensive care unit? In answering this question, the results of this study showed that the head nurses' educational needs included four dimensions, scientific, artistic, technical and organizational. Although, searching the resources for finding studies specifically done on educational needs or on head nurses' competency at the intensive care unit yield no result, yet the study by American organization of nurse executive (AONE) in 2002, showed providing care for the patient, improving the staff, managing the financial and human resources, compliance with the occupational regulations and standards, and strengthening the relation between the occupation and strategic planning as the responsibilities of a head nurse (15). In 2004, the same organization categorized the responsibilities of a first-rate nurse into three parts of business management, staff directing, and leadership and included the head nurses competency in each of these three parts (16).

In 2008, AONE and the American association of criticalcare nurses (AACN) rewrote the needed skills of a nurse director and took account of three major scopes of science, art and leadership as its framework (17). Moreover, Chase (2010), using a Katz managerial competency model, planned nurse directing competency courses consisting of five domains: technical, human, conceptual, directorial and financial, to which risk management, marketing management and knowledge of health care regulations was added afterwards (18).

Therefore, the required trainings must be planned and manipulated for achieving these competencies. As it is obvious, the results of the aforementioned studies are consistent with ours. However, their training is not specialized for head nurses at the intensive care unit. However, their common point has been the need for funding capability for head nurses and nurse directors, which was not in line with the results of our study because in our health system, the head nurses are not directly involved in finance and budgeting. It should be noted that in rela- tion to educational needs of head nurses at the intensive care unit, no research was found in our country.

However in one study, the educational needs of nursing managers at state hospitals was reported to be gaining knowledge on ethics and rules in nursing, information technology, qualitative examination of the units, improvement in the quality of nursing services, familiarity with the standards of structure, equipments and human resources, crisis management, health training, controlling hospital infections, communication skills, decision making and problem solving methods, and time management (19). Azimian (2002) too, took into consideration the change in the syllabus of the nursing management course in continuing and in-service educational programs (20).

The results of our study showed that the main aspects of head nurses' educational needs in the artistic dimension included skills in communication, creativity, critical thinking, controlling tension, fury, opposition, creating motivation in the staff, negotiation techniques, and eventually body language and public effect. Other studies too, have investigated skills in directing human resources, managing communication and effective behaviors, and participatory decision making as the artistic competencies of a head nurse (17). As evident, the above classification is similar to the results of the present study; for example, creating motivation in the staff is one of the directorship skills, or negotiation techniques, public effect, communication, controlling tension, fury, and the opposition are some of the managerial skill. However, what is the aforementioned art good for? Many nursing theoreticians have considered the artistic dimension of nursing, as an example, Shahsavari et al. has presented nursing as a serving art (21) and Johnson has thought about the meaning perception in dealing with patients and establishing a meaningful relationship as constituents of nursing art (22). In fact, nursing art refers to the creative and purposeful use of oneself based on the skills in transmitting feelings and concepts to others (23). The main reason for studying nursing is having personality traits like creativity and purposefulness, skill and mastery, communicating meaningfully, holism, care individualization, adaptation of experimental science with metaphysics and value while emphasizing ethics, harmony, rhythm and unity, power of analytical judgments besides transmission of feelings and concepts to others, concentration on mental processes and attention to interpretation, sensitivity, imagination and active participation, with the aim of improving mental and physical well-being. These personality traits justify the constituent subcategories of artistic needs in this study.

Our other significant finding was the need of head nurses in the intensive care unit for acquiring educational competence, particularly in the field of training the staff. In this relation, Palmer too, studied training the head nurses as directors for obtaining stable in-service education, and he counted them as more efficient teachers relative to others (4). 
One of the other findings of our study was the need for training spiritual care and creating a spiritual work environment, which was not referred to by other studies. Our religious belief regarding a positive spiritual relationship with the infinite power of God, which is believed to be always supporting man, (24) can justify this finding.

The data of this study revealed that to achieve managerial competency, the head nurses at the intensive care unit need scientific, artistic, technical, and organizational competence, the access to which is possible through education. Proper and continuous planning and implementation of in-service education based on these educational needs result in providing hospitals with head nurses having managerial competence for directing the intensive care units.

\section{Acknowledgments}

The authors acknowledge the faculty of medical sciences of Tarbiat Modares University for their financial support. The participants and the authorities of Mazandaran hospitals are specially appreciated for their cooperation in the collecting data.

\section{Footnotes}

Authors' Contribution:Study concept and design: Roghieh Nazari, Zohre Vanaki, Sima Mohammad Khan Kermanshahi and Ebrahim Hajizadeh; analysis and interpretation of data: Roghieh Nazari, Zohre Vanaki and Sima Mohammad Khan Kermanshahi; drafting of the manuscript: Roghieh Nazari; critical revision of the manuscript for important intellectual content: Zohre Vanaki and Sima Mohammad Khan Kermanshahi.

Funding/Support:Tarbiat Modares University.

\section{References}

1. Hawkins JW, Burke PJ, Steinberg S. Integrating practice issues in managed care into the curriculum: a Delphi survey. J Am Acad Nurse Pract. 2006;18(12):582-90. doi: 10.1111/j.17457599.2006.00181.x. [PubMed:17184311]

2. Ibarra V. Management education needs of head nurses. J Nurs Staff Dev. 1989;5(1):36-9. [PubMed: 2921619]

3. Adams D. Management needs of head nurses and supervisors: designing a continuing education course. J Contin Educ Nurs. 1991;22(1):16-20. [PubMed:1899259]

4. Palmer SP, Heaston S. Teaching the teacher program to assist nurse managers to educate nursing staff in Ecuadorian hospitals. Nurse Educ Pract. 2009;9(2):127-33. doi: 10.1016/j. nepr.20 08.10.002. [PubMed:19059007]

5. Davis N, Davis D, Bloch R. Continuing medical education: AMEE Education Guide No 35. Med Teach. 2008;30(7):652-66. doi: 10.1080/01421590802108323. [PubMed: 18777424]

6. Kim S, Dunkin BJ, Paige JT, Eggerstedt JM, Nicholas C, Vassilliou $\mathrm{MC}$, et al. What is the future of training in surgery? Needs assessment of national stakeholders. Surgery. 2014;156(3):707-17. doi: 10.1016/j.surg.2014.04.047. [PubMed:25175505]

7. Lin M, Santen SA, Yarris LM, Mullan P, Searle N, Rougas S, et al Development of a training needs assessment for an education scholarship fellowship in emergency medicine. Acad Emerg Med. 2012;19(12):1419-24. doi: 10.1111/acem.12035. [PubMed: 23216849]

8. Hewson-Conroy KM, Elliott D, Burrell AR. Quality and safety in intensive care-A means to an end is critical. Aust Crit Care. 2010;23(3):109-29. doi: 10.1016/j.aucc.2009.12.001. [PubMed: 20083413]

9. Thrall TH. Nurturing your nurse managers. Hosp Health Netw. 2006;80(4):71-2. [PubMed:16703834]

10. Ratnapalan S, Hilliard R. Needs assessment in postgraduate medical education: A review. Med Educ Online. 2002;7(8)

11. Crandall SJ. Using interviews as a needs assessment tool. Journal of Continuing Education in the Health Professions. 1998;18(3):155-62. doi:10.1002/chp.1340180305.

12. Vaismoradi M, Turunen H, Bondas T. Content analysis and thematic analysis: Implications for conducting a qualitative descriptive study. Nurs Health Sci. 2013;15(3):398-405. doi: 10.1111| nhs.12048. [PubMed:23480423]

13. Elo $S$, Kyngas $H$. The qualitative content analysis process. $J$ Adv Nurs. 2008;62(1):107-15. doi: 10.1111/j.1365-2648.2007.04569.x. [PubMed: 18352969]

14. Fitzpatrick JJ. Who should teach advanced practice nursing? Nurs Educ Perspect. 2002;23(6):277. [PubMed:12503465]

15. American Organization of Nurse Executives The role and functions of the hospital nurse manager. Nurs Manage. 1992;23(9):36-9.

16. American Organization of Nurse Executives Nurse executive competencies. Nurse Leader. 2005;15(22)

17. The American organization of nurse executives The AONE nurse executive competencies. 2011.

18. Chase LK. Nurse manager competencies (A thesis submitted in partial fulfillment of the requirements for the Doctor of Philosophy degree in Nursing). USA: Graduate College of The University of Iowa; 2010.

19. Abbaszadeh SMM, Nikbakht Nasrabadi AR, Vaskouei Eshkevari $\mathrm{KH}$. Assessing educational needs of nurse managers affiliated to state hospitals [In Persian]. Iran J Nurs Res. 2010;4(15):16-24.

20. Azimian J. Educational needs of nursing managers about quality assurance of nursing care in Qazvin teaching hospitals [In Persian]. J Qazvin Univ Med Sci Health Serv. 2002;22:75-80.

21. Shahsavari H, Salsali M, Mohammadpour A. Nursing as an art [In Persian]. HAYAT. 2010;16(1):23-33.

22. Johnson JL. A dialectical examination of nursing art. ANS Adv Nurs Sci.1994;17(1):1-14. [PubMed:7979261]

23. Jenner CA. The art of nursing: a concept analysis. Nurs Forum. 1997;32(4):5-11. [PubMed: 9534552]

24. Seligman ME, Csikszentmihalyi M. Positive psychology. An introduction. Am Psychol. 2000;55(1):5-14. [PubMed: 11392865] 